\title{
Transitivity Analysis of 2018 State of the Union Address by President Donald Trump
}

\author{
Jiahui Su \\ School of Humanities, Tiangong University, Tianjin, China \\ Email: 1172489412@qq.com
}

How to cite this paper: $\mathrm{Su}$, J.H. (2021) Transitivity Analysis of 2018 State of the Union Address by President Donald Trump. Open Access Library Journal, 8: e7563. https://doi.org/10.4236/oalib.1107563

Received: May 21, 2021

Accepted: June 14, 2021

Published: June 17, 2021

Copyright ( 2021 by author(s) and Open Access Library Inc.

This work is licensed under the Creative Commons Attribution International License (CC BY 4.0).

http://creativecommons.org/licenses/by/4.0/

(c) (i) Open Access

\begin{abstract}
The State of the Union Address refers to the annual report of the sitting president to congress, which is a representative political discourse. It mainly deals with the major issues in the United States that year, both at home and abroad and the policy measures are to be taken by the government. Transitivity system is a semantic system of ideational function and plays a very important role in discourse analysis. It expresses people's experience of the real world and the inner world in a number of processes and indicates the participants and environmental components involved in the process. This paper takes the transitivity system in Halliday's ideational functions as the theoretical framework and US President Donald Trump's 2018 State of the Union Address as the language material. It mainly analyzes the transitivity process, main participants, and environmental elements embodied in the speech and makes statistics on their distribution, and finally obtaining the reasons for the distribution is that Trump wants to get support by proving his ability.
\end{abstract}

\section{Subject Areas \\ Information Science}

\section{Keywords}

SOTU, SFG, Transitivity

\section{Introduction}

SOTU Address is one of the most important speeches in the United States. In order to maintain the rule and gain the support of the public, the president usually reflects his own political ideas and the policies of administration in his SOTU Address [1]. In a word, SOTU Address has a great influence on every as- 
pect of the United States. Before the emergence of Systemic Functional Grammar, many scholars mainly studied the SOTU Address from Appraisal theory, Critical Discourse Analysis, Polarity, and Translation. With the development of SFG, it is regarded as a scientific method of discourse analysis [2].

This paper analyzes Donald Trump's 2018 SOTU Address from a transitivity perspective to reveal the features of Trump's SOTU and the hidden deep meaning beneath the surface of his speech. It consists of three chapters. The second chapter mainly introduces Halliday's Systemic Functional Grammar and transitivity, the third chapter mainly analyzes Trump's 2018 SOTU Address, the fourth chapter makes a statistical analysis of the transitivity system in the SOTU Address, and the last chapter makes conclusions from this paper.

\section{Theoretical Basis}

It's a scientific tool to use Halliday's Systemic Functional Grammar in terms of discourse analysis. Thus, this chapter will make a detailed introduction to Systemic Functional Grammar, including three functions and transitivity.

\subsection{The Introduction of Halliday's Systemic Functional Grammar}

M. A. K. Halliday introduces Systemic Functional Linguistics in 1985. It is a sociologically oriented functional linguistic approach, consisting of Systemic Grammar and Functional Grammar. In Systemic Functional Linguistics, language is considered as the product of social activities and it provides considerable functions. It is based on two facts: 1) language users make choices in a system and try to realize different semantic functions in social interaction; 2) language cannot be separated from the social activities of human beings. Systemic Grammar emphasizes expounding the interior relations of language. Speakers can select the proper language forms to convey their information. As for Functional Grammar, Halliday considers that language is what it is since it has to serve certain functions. In other words, as to children, language development refers to mastery of linguistic functions. As to adults, there are three functions, ideational function, interpersonal function, textual function [3].

The ideational function is applied for conveying new information, to communicate content that is unknown to the hearer. The ideational function mainly consists of "transitivity" and "voice". Transitivity simply refers to the grammar of the clause in its ideational aspect. It consists of six different processes: Material, Behavioral, Mental, Verbal, Relational, and Existential Process.

The interpersonal function embodies all uses of language to express social and personal relationships [3]. This includes the various ways the speaker enters a speech situation and performs a speech act. Because the clause is not confined to the expression of transitivity, there are non-ideational elements in the adult language system. Interpersonal function is realized by mood and modality [4].

The textual function means that language has mechanisms to make any 
stretch of spoken or written discourse into a coherent and unified text and at the same time, make a living passage different from a random list of sentences. Although two sentences may have exactly the same ideational and interpersonal functions, they may be different in textual coherence.

\subsection{The Introduction of Transitivity}

The ideational function consists of transitivity and voice. Transitivity refers to the grammar of the clause in its ideational aspects. It is a semantic system, whose function is to divide what people see, hear and do in the real world into several processes and identify participants and circumstantial elements involved in various processes, such as material process, relational process, behavioural process, verbal process, mental process and existential process [4].

\subsubsection{Six Transitivity Processes}

In this part, it will describe the definition of six processes in detail and give specific examples for each process.

\section{Material Process}

Material Process is a process of doing something. It is about our experience of the material world, including an actor, an action verb (kick, clean, open), and the goal. The actor is the logical subject of the sentence, the goal is the logical direct object, such as the following examples:

Example 1:

\begin{tabular}{ccc}
\hline Marry & cleaned & her house. \\
Actor & Process & Goal \\
\hline
\end{tabular}

\section{Mental Process}

Mental process is the process of sensing. It is about our own consciousness of the experiential world, including two participants, sensor and phenomenon. The verb refers to "hear", "understand", "hate", "like" and so on.

Example 2:

\begin{tabular}{ccc}
\hline I & like & his clothes \\
Sensor & Process & phenomenon \\
\hline
\end{tabular}

\section{Relational Process}

Relational process is the process that reflects the relationship between things or it is a process of being or becoming. The relational process has two types: attributive and identifying. The former refers to which attributive an entity has or which type it belongs to (example 3). The latter identifies two entities' properties. Each of the two types can be separated into three types: intensive, circumstantial and possessive [3]. 


\section{Example 3:}

\begin{tabular}{ccc}
\hline I & am & a teacher. \\
Carrier & Process & Attribute \\
\hline
\end{tabular}

\section{Example 4:}

\begin{tabular}{ccc}
\hline Spring & follows & Summer. \\
Identified & Process & Identifier. \\
\hline
\end{tabular}

\section{Behavioural Process}

Behavioural process is a process of behaving that has something to do with physiological activities, like breathing, coughing, smiling, dreaming and so on. Only one participant or we call it behaver can be seen in the behavioural process and the behaver is usually human being [3].

Example 5:

\begin{tabular}{ccc}
\hline Tom & smiled & loudly. \\
Behaver & Process & circumstantial \\
\hline
\end{tabular}

\section{Verbal Process}

Verbal process is a process of saying. Saying conveys any kind of symbolic exchange of meaning. The central verbal process is easily recognized because it is connected with the transfer of messages through languages.

Example 6:

\begin{tabular}{cccc}
\hline Mom & told & me & a story. \\
Sayer & Process & Receiver & Verbiage \\
\hline
\end{tabular}

\section{Existential Process}

Existential process is a process of existing. There is an existent in every existential process, like "there are", "exist".

\section{Example 7:}

\begin{tabular}{ccc}
\hline There are & Many books & on the table. \\
Process & Existent & Circumstantial \\
\hline
\end{tabular}

\subsubsection{Participants}

The participants are directly involved in the process. Every experiential type of clause has at least one participant and some types have three participants [5].

In the material process, the participant we can call the actor and goal, representing 
"happening".

In the mental process, the participants are regarded as sensor and phenomenon, representing "consciousness". Phenomenon is the participant that is felt, thought, wanted or perceived.

In the relational process, the participants refer to carrier, attribute, identifier, identified.

In behavioural process, the involved participant is behaver.

In verbal process, the participants are sayer and receiver. In some cases, the participant is regarded as target. The message can be concluded by a nominal group functioning as a participant in the process, called verbiage.

In existential process, the participant we called is existent, representing the existing of something or event.

\subsubsection{Circumstantial Elements}

Circumstantial Elements refer to the expression of meaning to the environment, including time, place, ways, degree, comparison, accompany, casual, identity language components [6]. The most familiar categories of circumstance are place and time. They can be regarded in terms of either points or lines (location or point: when and where; extent or line: how long/how often and how far). Another familiar category of cause is the manner "how", including the type of quality, means, degree and comparison. The category of cause is a fairly complex one, including reason, purpose and behalf. Closely related to cause is the contingency: condition, default and concession fall into this category. Accompaniment answers the question "who/what with" role basically answers the question "what as" although they include a small sub-category of product answering the question "what into", There are two final groups, both of which have particular links with verbal and mental processes.

\section{Transitivity Analysis of 2018 SOTU Address}

In this chapter, it will analyze transitivity system in 2018 SOTU Address in detail. It will take examples from 2018 SOTU Address and then make a concrete analysis in terms of six processes, participants and circumstantial elements.

\subsection{Analysis of Transitivity Process in 2018 SOTU Address}

Material Process is a process of doing something, including actor, process and goal. In Donald Trump's 2018 SOTU Address, there are many material processes to describe the present situation, for example:

1) We endured floods and fires and storms.

2) Since the election, we have created 2.4 million new jobs, including 200,000 new jobs in manufacturing alone. After years of wage stagnation, we are finally seeing rising wages.

3) Since we passed tax cuts, roughly 3 million workers have already gotten tax cut bonuses.

4) To speed access to breakthrough cures and affordable generic drugs, last 
year the FDA approved more new and generic drugs and medical devices than ever before in our history.

5) He decided to change that, and started a movement that has now placed 40,000 flags at the graves of our great heroes.

6) David faced down walls of flame to rescue almost 60 children trapped at a California summer camp threatened by wildfires.

7) He commanded an operation track down gang member on Long Island. His team has arrested nearly 400, including more than 220 from MS-13.

From the first example, we can draw a conclusion that Trump attached importance to the natural disasters suffered by the people at home and used "we" to show his sympathy and presence with the people. From the second, third and fourth example, Trump emphasized people's livelihood, tax reform and medical treatment to get support. From the fifth, sixth and seventh example, he used the heroic events to inspire the courageous dedication of citizens.

8) Unemployment claims have hit a 45-year low. African-American unemployment stands at the lowest rate over recorded, and Hispanic American unemployment has also reached the lowest levels in history.

9) We enacted the biggest tax cuts and reforms in American history.

10) We passed tax cuts, roughly 3 million workers have already gotten tax cut bonuses.

12) We are removing a particularly brutal tax code for Americans who earn less than $\$ 50,000$ each year.

13) We reduced the business tax rate from $35 \%$ to $21 \%$.

14) We are serving our brave veterans, including giving our veterans choice in their healthcare decisions.

From the eighth to thirteenth, it can be found that Trump focused on the development of economy by tax reform to stimulate development so that he wants to consolidate his power by defending the interests of the bourgeoisie [7]. Because he used to be an experienced businessman before being a president. In the fourteenth example, he also attaches great importance to safeguarding the interests of the military. It is a good way to protect his power.

15) We have proposed new legislation that will fix our immigration laws, and support our ICE and Border Patrol Agents, so that this cannot ever happen again.

16) I have vowed to add 10,000 new border customs enforcement agents.

17) My administration is committed to fighting the drug epidemic and helping get treatment for those in need.

In the fifteenth to seventeenth, it can be found that Trump has sought to protect domestic security by changing immigration laws and adding customs officers to protect people from legal loopholes. He also works to crack down on drug and help drug addicts to protect people's heath and achieve national stability.

Mental process focuses on one's inner world and refers to people's emotion, feeling and cognition, involving the following verbs: like, hate, want, regret and 
so on. In this part, there are some examples.

18) Tonight, I want to talk about what kind of future we are going to have and what kind of Nation we are going to be.

19) People who are terminally ill should not have to go from country to seek a cure-I want to give them a chance right here at home.

20) I want our youth to grow up to achieve great things. I want our poor to have their chance to rise.

In these examples, the subject "I" is the sensor so that we can find that Trump wants to do something for people and expresses his ability and wishes. And the phenomena are "talk about what kind of future we are going to have and what kind of Nation we are going to be", "give them a chance", "grow up to achieve great things" and "have their chance to rise". So we can get the conclusion that Trump tries his best to lead people to realize American dream [7].

Relational process is the process of being. It can be divided into two categories, including attributive and identifying. Besides, the two categories consist of three types which are intensive, circumstantial elements and possessive. Here are typical examples.

21) Small business confidence is at an all-time high.

22) That is great news for American's $401 \mathrm{k}$, retirement, pension and college saving accounts.

23) Now, the first $\$ 24,000$ earned by a married couple is completely tax-free.

24) This April will be the last time you ever file under the old broken system-and millions of Americans will have more take-home pay starting next month.

In this part, the carriers are respectively "Small business", "That", "the first $\$ 24,000$ earned by a married couple", “This April”. The attributes are "at all-time high", “great news for American's $401 \mathrm{k}$, retirement, pension and college saving accounts", "tax-free", "the last time you ever file under the old broken system". So from these typical relational processes, we can discover that Trump wants to show his great achievements in the past year. At the same time, he also wants to express his ability to people. He can make America great again [7].

25) No people on Earth are so fearless, or daring or determined as Americans.

26) The state of our Union is strong because our people are strong.

In these two instances, the carriers are "No people", "The state of our Union". The processes are "are" and "is". The attributes are "fearless, or daring or determined as Americans", "strong". It is found that Trump emphasizes the relationship between people and him. In his view, American citizens are very important in terms of the development of America. He tries his best to unite people to make America better.

Verbal process is a process of saying. It conveys the symbolic meaning. For example:

27) And we celebrate our police, our military, and our amazing veterans as heroes who deserve our total and unwavering support. 
28) I call upon all of us to set aside our differences, to seek out common ground, and to summon the unity we need to deliver for the people we were elected to serve.

29) I call on the Congress to empower every Cabinet Secretary with the authority to reward good workers.

30) I am calling on the Congress to produce a bill that generates at least $\$ 1.5$ trillion for the new infrastructure investment we need.

31) I am calling on the Congress to finally close the deadly loopholes that have allowed MS-13, and other criminals to break into our country.

In example 27, the sayer is "we", the process is "celebrate", the receiver is "police, military, veterans". In the example28 to 31 , Trump used the verb "call on", and the receiver is "Congress". As a result, we can find that Trump tries to make people believe him by celebrating heroes and encourages government officials to work hard and take responsibility to make America better. Meanwhile, he attaches importance to the construction of infrastructure and safeguards the security of domestic for national development.

32) I am asking both parties to come together to give us the safe, fast, reliable, and modern infrastructure our economy needs and our people deserve.

33) I am asking the Congress to end the dangerous defense sequester and fully fund our great military.

34) I am also asking the Congress to ensure that in the fight against ISIS and al-Qa'ida, we continue to have all necessary power to detain terrorists-whatever we chase them down.

35) I am asking the Congress to address the fundamental flaws in the terrible Iran nuclear deal.

36) I will not repeat the mistakes of past administrations that got us into this dangerous position.

In these instances, he uses the verb "ask" to express his forceful, convincible and attractive words. What's more, he puts the national security interests first to earn the trust and support of domestic people. In the last example, he uses the verb "will not repeat" to reassure people and it shows that he can learn from it.

Behavioral process refers to a process of psychology and physiology, including laughing, snivelling, glaring, guffawing and so on. Here are some examples about behavioral process in Trump's 2018 SOTU Address.

37) We have seen the beauty of America's soul, and the steel in America's spine.

38) We saw the volunteers of the "Cajun Navy", racing to the rescue with their fishing boats to save people in the aftermath of a devastating hurricane.

39) We saw strangers shielding strangers from a hail of gunfire on the Las Vegas strip.

40) We heard tales of Americans like Coast Guard Petty Officer Leppert.

In the above sentences, "see", "hear" are the process and "we" is the behavior. From the above examples, we can find that behavioral processes are less used. By listing some heroic deeds, Trump encourages his Americans to be brave and 
strong. This is the core of the national spirit. Because of them, the country is stronger.

Existential process refers to a process of projecting something that exists. The typical instance is the sentence pattern of "There be". For example:

41) If there is a mountain, we climb it. If there is a frontier, we cross it. If there is a challenge, we tame it. If there is an opportunity, we seize it.

42) There has never been a better time to start living the American Dream.

Trump uses the two sentences to show the current situation and exists. In example 41, he uses the same sentence pattern, using "mountain", "frontier", "challenge" as the existent to aim to show that no amount of hardship can stop us from realizing the American dream. And in the last sentence, "opportunity" is the existent. It also shows Trump's expectation. In example 42, "a better time" is the existent. It's not hard to find him urging people to jump into American dream.

\subsection{Analysis of Participants in 2018 SOTU Address}

This section focuses on the participants in the process of 2018 SOTU Address. The use of process is the representative feature of discourse, and the interrelation between processes and participants reflects the characteristics of specific discourse. It is involved in first personal pronouns "I, me, we, us, our", the second personal pronouns "you, your" and the third personal pronouns "they, them, their".

\subsubsection{Participants of the First Person}

From the whole address, Trump uses many the first person who can close the distance with people and his purpose is to tell people that he is always with you. Here are some typical examples:

43) We endured floods and fires and storms.

44) This is our new American moment.

45) Let us open great vocational schools so our future workers can learn a craft and realize their full potential.

In the 2018 SOTU Address, Trump uses “we, our, us" to express no matter what happens, he will always be with the people. He gives people moral support. Besides, "we, us, our" also shows that Trump always puts the interests of the people first.

46) I also took an action endorsed unanimously by the Senate just months before.

47) I am proud to report that...

48) I will not repeat...

49) My administration has already removed...

In the all above instances, "I, my" refers to Trump. He uses this to express ideas and feelings and decisions about future development. Although it makes people feel distant. It is a good way to earn thunderous applause and support 
from people.

\subsubsection{Participants of the Second Person}

The second person "you, your" comes across as respectful and unfriendly. For instance:

50) Your great sacrifice is an inspiration to us all.

51) So to every citizen watching at home tonight-no matter where you have been, or where you come from, this is your time.

52) If you work hard, if you believe in yourself, if you believe in America, then you can dream anything...

In example 50, Trump uses "your" to show respect to those who have contributed to the country. In the next two examples, we can see that he is standing in line with the whole Americans and expresses a kind of inspiration and sincerity to citizens.

\subsubsection{Paticipants of the Third Person}

In the 2018 SOTU Address, the use of the third person is symbolic. Some typical sentences are as follows:

53) They work in every trade. They sacrifice to raise a family. They care for our children at home. They defend our flag abroad.

54) They are Americans.

55) My duty...to protect their safety, their families, their communities and their right to the American Dream.

56) Our task is to respect them, to listen to them...

In these sentences, the third person "they, their" refers to the work families. Because Trump is a businessman, he is on behalf of the interests of middle-class families. Thus it can be seen that he attaches great importance to protect middle-class so as to consolidate domestic rule.

\subsection{Circumstantial Elements in 2018 SOTU Address}

Circumstantial elements usually are not compulsory parts of the clause. They are the augments of a clause to some extent-temporally, spatially, casually, and so on, and they are not direct parts in the process [8]. The typical forms are adverbial groups and prepositional phrases. In this part, I will analyze the main circumstantial elements in the processes, including location circumstance, manner circumstance and cause circumstance.

\subsubsection{Location Circumstance}

Location determines the position of the process in the extension of time and space. The place refers to where it unfolds or the time when it unfolds. The general question of location refers to where and when. Place is not just static location in space, but the source, path, destination of movement [8].

57) Less than 1 year...Over the last year...

58) Tonight...Today 
59) Last month...

60) In Detroit, I halted...

From the above examples we can find that these adverbial groups and prepositional phrases are typical structure of location circumstance. "Tonight" refers to a concrete time. "Today" refers to universal time. "Last month, Less than 1 year, Over the last year" refers to past static time. "In Detroit" refers to the exact position. Location circumstance makes the address smoothly and completely. It's very indispensable to identify each process and have a fundamental understanding.

\subsubsection{Manner Circumstance}

Manner circumstance is the way to realize the process, including means, quality, comparison and degree. Here are some examples:

61) So let us begin tonight by recognizing that...

62) ...had already taken swift action.

63) ...bring out the best in America.

64) Just as I promised...

In the first example, "by recognizing that" refers to means of manner circumstance. It makes all Americans strike a chord. In the second example, "swift action" refers to degree of manner circumstance. It describes the features of material process. In the third example, "the best" refers to comparison of manner circumstance. It shows the role of participants in this process. And in the last sentence, "just as" refers to quality of manner circumstance. It represents the feature of the process.

\subsubsection{Cause Circumstance}

The circumstantial element of cause expounds the reason why the process is actualized. It is composed of reason, purpose, and behalf. For instance:

$65)$...so that this cannot ever happen again.

66) For this reason, I am asking...

In the above sentences, "so that" refers to the purpose of cause circumstance, representing the intended conditions of material processes. "For this reason" refers to the reason of cause circumstance. It can contribute to the actualization of the process.

\section{Distribution of Transitivity System in 2018 SOTU Address}

This part is mainly about the statistics of distribution of transitivity system in 2018 SOTU Address, including transitivity processes, main participants and circumstantial elements.

\subsection{Distribution of Transitivity Processes in 2018 SOTU Address}

The distribution of six transitivity processes shows that Trump concerns the interests of people and the development of nation and the realization of American Dream. It is presented in Table 1. 
Table 1. Distribution of six processes in 2018 SOTU address.

\begin{tabular}{cccc}
\hline Name & Types & Number & Percentages \\
\hline Material & 259 & $61.4 \%$ \\
Mental & 55 & $13 \%$ \\
Relational & 76 & $18 \%$ \\
Six Processes & Verbal & 22 & $5.3 \%$ \\
& Behavioral & 6 & $1.4 \%$ \\
& Existential & 4 & $0.9 \%$ \\
& Total & 422 & $100 \%$ \\
\hline
\end{tabular}

From this table, we can find that material process takes up $61.4 \%$ and it is the highest. Relational process takes up $18 \%$ and mental process takes up $13 \%$.We can get a conclusion that these three processes account for the highest proposition in 2018 SOTU Address. Specifically, material process shows what America has happened and reflects what Americans have done. At the same time, material process reflects Trump's ideology. In 2018 SOTU Address, Trump uses many material processes to describe the current situation and show great achievements. This is the topic what people want to know, and which can arouse people's emotional resonance. Meanwhile, He focuses on tax reform and describes relevant measures through a large number of material processes to safeguard the interests of the middle class. It can be seen from this that he is an experienced businessman. It is an effective way to maintain the rule of the middle class. Besides, he also attaches great importance to the security and stability of the country, and improves immigration laws to avoid the recurrence of incidents that caused people due to legal loopholes. In fact, he is solving the most concerning problems to gain the support of the people and maintain his rule. Finally, he talks about terrorist organizations and nuclear missiles. He proposes that the development of national defense must update nuclear arsenals. We will combat all terrorist forces and forces that affect the sovereignty of the nation.

Relational process is in the second rank. In 2018 SOTU Address, Trump uses a large number of processes to make people know his ability. He wants Americans to believe that he is capable of making America better and America Dream realize. At the same time, a large number of relational processes also show that he attaches great importance to the relationship with people. People's interests are vital important.

Mental process ranks third. It represents Trump's plans. He focuses on the price of prescription drugs, available treatment for the poor and the future of America. He hopes that the government can take measures to help the vulnerable groups to solve the difficulties, and calls on the younger generation to contribute more to the country and improve the lives of the poor. So, we can find that Trump wants to show he can make American Dream realize. He also gets 
the support from people through this.

\subsection{Distribution of Participants in 2018 SOTU Address}

The following Table represents the percentages of participants in the 2018SOTU Address.

From Table 2, the first pronouns take up the highest. The third pronoun ranks second and the second pronoun ranks third. Based on this data, Trump uses many the first pronouns to let people feel that he is putting people's interests first. And it's beneficial to make people accept his plans and control people's awareness. After all, America faces many challenges at home and abroad. Trump is much more stressful than ever before. As to the third pronouns, "they, them, their" refers to the opposite groups who are going to be isolated or punished. It can be seen that Trump is very concerned about special groups and forces. For positive groups, he calls for taking measures to help them. As for the opposition, he calls for congress to improve laws to punish them. The second person is the least used. In Trump's address, he tries to express respect and wishes to people who make contributions to nation. This shows us his quality.

\subsection{Distribution of Circumstantial Elements in 2018 SOTU Address}

Here are the data of circumstantial elements in 2018 SOTU Address.

Based on Table 3, three main circumstantial elements take up respectively $43 \%, 23 \%, 34 \%$. It can be found that the location circumstances rank first. In Trump's address, he uses much specific time to describe what America has happened in the past and the current situation at present and his plans in the future. He uses clear thinking to make himself better understood. The manner circumstance ranks second. Through some phrases and prepositions, the audience can understand his meaning clearly. From these two data, we can know that he has a very serious and rigorous attitude towards state affairs. And the cause circumstance accounts for the smallest preposition. By some phrases that express cause and effect, he spares no efforts to solve the problems. Importantly, he is very satisfied with what he has achieved. In other words, he is also trying to get people's recognition.

Table 2. Distribution of participants in 2018 SOTU address.

\begin{tabular}{ccc}
\hline Participants & Number & Percentage \\
\hline We/us/our & 235 & $60.6 \%$ \\
I/my & 89 & $23 \%$ \\
They/them/their & 38 & $9.8 \%$ \\
You/your & 25 & $6.6 \%$ \\
Total & 387 & $100 \%$
\end{tabular}


Table 3. Distribution of circumstantial elements in 2018 SOTU Address.

\begin{tabular}{ccc}
\hline Circumstantial Elements & Number & Percentage \\
\hline Location & 86 & $43 \%$ \\
Cause & 45 & $23 \%$ \\
Manner & 68 & $34 \%$ \\
Total & 199 & $100 \%$ \\
\hline
\end{tabular}

\section{Conclusions}

Through the analysis of transitivity in 2018 SOTU Address, we can draw the following conclusions. Firstly, Trump uses short sentences to express the daily life of Americans. In his speech, material process (61.4\%), relational process (18\%), and mental process (13\%) are three main processes. From these three processes, the current situation and challenges in the United States are clearly expressed. Especially, transitivity processes prove to us that Trump himself is more competent.

Secondly, based on the distribution of participants, the first person (83.6\%) ranks first. The extensive use of the first person, including singular and plural can greatly shorten the distance with people. In other words, transitivity processes make Trump's speech more skillful.

Besides, based on the data of circumstantial elements, the main use is location circumstance, manner circumstance, cause circumstance. They occupy separately $43 \%, 34 \%, 23 \%$. When Trump describes important events, many specific times and places are employed. It suggests Trump's attitude. So, the transitivity system can make Trump's political ideas present directly.

In a word, although this paper makes a detailed analysis of the transitivity system in 2018 SOTU Address, there are still many limitations due to my academic ability. It's important to concentrate on these limitations for further study.

\section{Acknowledgements}

It is a significant and unforgettable experience for me to spend such a long time on writing, modifying my paper. Many kind-hearted people give me a great amount of help, professional advice and encouragement. Thus, here I would like to express my sincere gratitude to them.

First of all, I will show my sincere thanks to my tutor Li Aina who has given me invaluable guidance and constant support and encouragement throughout the whole processes.

Secondly, I also owe a special debt of gratitude to all the professors in Foreign Language Department, from whose devoted teaching and enlightening lectures I have benefited a lot and academically prepared for the paper.

Lastly, I should finally like to express my gratitude to my beloved family and my boy friend who have always been helping me out of difficulties and supporting without a word. 


\section{Conflicts of Interest}

The author declares no conflicts of interest regarding the publication of this paper.

\section{References}

[1] Fang, X. (2016) Transitivity Analysis in the State of the Union Speech of Barack Obama 2015. MSc. Thesis, Zhengzhou University, Zhengzhou.

[2] Huang, G.W. (2000) A Review of the 40 years Development of Halliday Systemic Functional Linguistics. Foreign Language Teaching and Linguistics Research, 15-21

[3] Hu, Z.L., Zhu, Y.S., et al. (2017) Introduction to Systemic Functional Linguistics. Third Edition, Peking University Press, Beijing.

[4] Hu, Z.L. (2005) System and Function of Language. Peking University Press, Beijing.

[5] Halliday, M.A.K. (2000) An Introduction to Functional Grammar. Foreign Language Teaching and Research Press, Beijing.

[6] Halliday, M.A.K. and Kirkwood, M.A. (1986) Notes on Transitivity and Themes in English. Journal of Linguistics, 3, 37-81.

[7] Hu, H. (2019) Analysis of the State of the Union Speech 2018 from the Perspective of System Functional Grammar. MSc. Thesis, Jiangxi University of Finance and Economics, Jiangxi.

[8] Halliday, M.A.K. and Matthiessen, C.M.I.M. (2014) Introduction to Functional Grammar. Fourth Edition, Routledge, Abingdon. 